O $\quad$ R I I G I N

$\begin{array}{lllllll}A & R & T & \text { I } & \mathrm{C} & \mathrm{L} & \mathrm{E}\end{array}$

\title{
Underdiagnosis of anaphylaxis in the emergency department: misdiagnosed or miscoded?
}

\author{
Hilal Hocagil \\ Evvah Karakilic \\ Cuneyt Hocagil \\ Huleyde Senlikci \\ Fatih Buyukcam
}

\begin{abstract}
Objectives To distinguish allergic reactions and anaphylaxis, and to highlight the importance of anaphylaxis.

Design Case series.

Setting Adult emergency department of the medical faculty of Hacettepe University, Ankara, Turkey.

Patients Adults admitted to the emergency department between 1 May 2005 and 30 April 2010 with allergic diseases considered to be anaphylaxis or anaphylactic reactions.

Main outcome measures Patient age, gender, possible cause(s) of allergy, organ involvement, treatment, and physical examination findings.

Results Although recorded physical examination findings of patients were consistent with anaphylaxis, 88 patients were not diagnosed as having this condition. All patients in this study group were evaluated in the emergency department facility and did not consult or were not referred to any other department or specialist. In all, 79 (90\%) of them were discharged in the first 12 hours, $5(6 \%)$ after 12 to 24 hours, and 4 (5\%) after 24 hours. None of these patients died.

Conclusion Emergency physicians should be better able to recognise the clinical features of anaphylaxis, so as to treat the episode promptly and appropriately. Delay in diagnoses could lead to incomplete treatment and even be fatal.
\end{abstract}

Key words
Anaphylaxis; Diagnosis; Emergency service, hospital

Hong Kong Med J 2013;19:429-33 DOI: $10.12809 / \mathrm{hkmj} 133895$

Department of Emergency Medicine, Dr Lutfi Kirdar Kartal Education and Research Hospital, Istanbul, Turkey H Hocagil, MD

Department of Emergency Medicine, Ankara Numune Education and Research Hospital, Ankara, Turkey E Karakilic, MD

Department of Emergency Medicine, Marmara University Pendik Education and Research Hospital, Istanbul, Turkey

C Hocagil, MD

Department of Emergency Medicine, Hacettepe University School of Medicine, Ankara, Turkey H Senlikci, MD

Department of Emergency Medicine,

Ankara Diskapi Yildirim Beyazit

Education and Research Hospital, Ankara, Turkey F Buyukcam, MD

Correspondence to: Dr E Karakilic Email: evvahka@gmail.com

\section{Introduction}

Anaphylaxis is a severe, life-threatening generalised systemic hypersensitivity reaction that appears suddenly following contact with an allergen. It is described as immune-mediated anaphylaxis when it occurs in relation to immunoglobulin (Ig) E, IgG, complement or immune complexes. Similar reactions without a recognised immunological basis are known as anaphylactoid reactions. ${ }^{1}$ From a pathophysiological point of view, immunemediated anaphylaxis arises as a result of mast cell degranulation relating to IgE, which causes the release of inflammatory immune mediators. These mediators induce peripheral vasodilatation and an increase in vascular permeability, increased mucus production, and contraction of bronchial smooth muscles. ${ }^{2}$ Although anaphylactoid reactions may arise with no previous contact with an allergen (ie sensitisation) and independently of IgE (or other proteins involved in immunological mechanisms), clinically they manifest as anaphylaxis. ${ }^{2}$

Numerous agents play a role in the aetiology of anaphylaxis. Such reactions can be provoked by foods such as peanuts, shellfish, fish, milk and eggs; drugs such as betalactam antibiotics, non-steroidal anti-inflammatory drugs, biological agents, poisons from bug bites and contrast agents. Inhaled pollens can also give rise to anaphylaxis by causing IgE-mediated reactions. Physical factors such as exercise, cold, heat and sunlight, and some 


\section{急診室中過敏性反應的診斷不足：是誤診還是 編碼錯誤?}

目的 分辨敏感和過敏性反應, 以及討論過敏性反應的重要 性。

設計 病例系列。

安排 土耳其安卡拉哈斯特帕 (Hacettepe) 大學中的成人急 診醫學系。

患者 2005 年5月1日至2010年4月30日期間，因敏感症狀被 認為是過敏或過敏性反應而送入急症室的病人。

主要結果測量 患者年齡、性別、可能的致敏原、受累的器官、治療 和體檢結果。

結果 雖然體檢結果顯示病人的症狀與過敏性反應吻合, 但 有 88 名患者被診斷為其他疾病。本研究的所有患者在 急症室進行評估, 並沒有諮詢或轉介至其他部門或專 科醫生。患者中有 79 人 ( $90 \%$ ) 在入急症室後的 12 小 時內出院, 另 5 人 $(6 \%)$ 於 12 至 24 小時內出院, 4 人 （5\%）於 24 小時後出院。沒有患者死亡。

結論 急症室醫生要熟悉過敏性反應的臨床特點, 以便及時 施以適當治療。延革診斷很可能引致不完全的治療甚 至死亡。
An allergy is a hypersensitivity disorder of the immune system, and an allergic reaction occurs when a person's immune system reacts abnormally against a harmless substance in the environment. ${ }^{6}$ Anaphylaxis is a relatively rare occurrence and can often be confused with a severe allergic reaction. ${ }^{7}$ It is important to understand the differences, so as to render appropriate care for the patient who is undergoing these health issues. Anaphylaxis is a sudden and severe allergic reaction that occurs within minutes of exposure, ${ }^{1}$ for which immediate medical attention is needed. It can get worse very quickly and lead to death within 15 minutes if treatment is not received. An estimated 1.24 to $16.8 \%$ of the population of the United States is considered 'at risk' of having an anaphylactic reaction if exposed to one or more allergens, especially penicillin and insect stings. ${ }^{8}$

In this study, we retrospectively evaluated the files of patients diagnosed with allergic reactions in the ED and determined patients who should have been diagnosed with anaphylaxis based on history and physical examination findings but diagnosed as having only an allergic disease. Our aim was to highlight the importance of anaphylaxis, which may take a fatal course, and increase awareness of features that distinguish it from simple allergic reactions not regarded as anaphylaxis.

drugs (ethanol, opioids, $\beta$-adrenoceptor antagonists) sometimes augment anaphylaxis through nonallergic mechanisms. ${ }^{3}$

Clinically, anaphylactic reactions are systemic reactions that threaten life, frequently involve the respiratory and cardiovascular systems, and are accompanied by diffuse urticaria and angioedema. In addition, there may also be gastro-intestinal and central nervous system manifestations. However, due to the fact that clinical findings vary markedly from patient to patient, sometimes the diagnosis is difficult. A universally accepted definition was therefore created with the consensus of many organisations interested in this condition. A summary of these clinical criteria necessary for the diagnosis of anaphylaxis is given in the Box. ${ }^{4,5}$

When there are multi-system symptoms and typical physical findings in a patient that develop quickly following exposure to a well-known allergen (such as a bee sting), the diagnosis of anaphylaxis can be readily made. Nevertheless, late occurrence of symptoms, symptoms akin to a vasovagal reaction, or symptoms more usually associated with another disease (such as asthma) may complicate diagnosis. In addition, patients may be labelled with a diagnosis other than anaphylaxis in the emergency department (ED), whenever the cause is not completely known (as in cases referred to as having food allergy).

\section{Methods}

Of patients admitted to the adult ED of the medical faculty of Hacettepe University, Ankara, Turkey (nearly 42000 per year), those with possible allergic diseases between 1 May 2005 and 30 April 2010 were included in this study. The International Classification of Diseases-10 codes associated with possible allergic reactions are listed in Table 1 . These codes were used to search computer records and 1076 patients were identified. None of these patients were recorded as having had anaphylaxis or anaphylactic shock. Then we searched their medical records and retrieved 816 patient files/folders to look for findings that conformed with criteria for the diagnosis of anaphylaxis $\left(\mathrm{Box}^{4,5}\right)$. Three of the researchers performed this review process, though inter-reviewer variation was not assessed, which is a limitation of our study. By this means, patients conforming to the diagnosis of anaphylaxis were identified. Each patient record was assessed in terms of age, gender, possible cause, organ involvement, receipt of treatment, and in-hospital death. Re-attendance due to a possible biphasic reaction from anaphylaxis was also searched for.

All categorical variables were analysed as frequencies and percentages, using the Statistical Package for the Social Sciences (Windows version 15.0; SPSS Inc, Chicago [IL], US). 
BOX. Clinical criteria for diagnosing anaphylaxis ${ }^{4,5}$

Anaphylaxis is highly likely when any one of the following three criteria is fulfilled:

(1) Acute onset of an illness (minutes to several hours) with involvement of the skin, mucosal tissue, or both (eg generalised hives, pruritus or flushing, swollen lips-tongue-uvula) and at least one of the following:

(a) Respiratory compromise (eg dyspnoea, wheeze-bronchospasm, stridor, reduced peak expiratory flow, hypoxaemia)

(b) Reduced blood pressure or associated symptoms of end-organ dysfunction (eg hypotonia [collapse], syncope, incontinence)

(2) Two or more of the following that occur rapidly after exposure to a likely allergen for that patient (minutes to several hours):

(a) Involvement of the skin-mucosal tissue (eg generalised hives, itch-flush, swollen lips-tongue-uvula)

(b) Respiratory compromise (eg dyspnoea, wheeze-bronchospasm, stridor, reduced peak expiratory flow, hypoxaemia)

(c) Reduced blood pressure or associated symptoms (eg hypotonia [collapse], syncope, incontinence)

(d) Persistent gastro-intestinal symptoms (eg crampy abdominal pain, vomiting)

(3) Reduced blood pressure after exposure to a known allergen for that patient (minutes to several hours):

(a) Infants and children: low systolic blood pressure (age-specific) or greater than $30 \%$ decrease in systolic blood pressure*

(b) Adults: systolic blood pressure of $<90 \mathrm{~mm} \mathrm{Hg}$ or $>30 \%$ decrease from that person's baseline

* Low systolic blood pressure for children is defined as $<70 \mathrm{~mm} \mathrm{Hg}$ from 1 month to 1 year, $<(70 \mathrm{~mm} \mathrm{Hg}+[2 \times$ age in years]) from $1 \mathrm{to} 10$ years, and $<90 \mathrm{~mm} \mathrm{Hg}$ from 11 to 17 years

TABLE I. The International Classification of Diseases-10 codes (2010) for allergic conditions

\begin{tabular}{|c|c|}
\hline Condition & ICD 10 codes \\
\hline Adverse effects, not elsewhere classified & $\begin{array}{l}\text { T78.0 Anaphylactic shock due to adverse food reaction } \\
\text { T78.1 Other adverse food reactions, not elsewhere classified } \\
\text { T78.2 Anaphylactic shock, unspecified } \\
\text { T78.4 Allergy, unspecified } \\
\text { T78.8 Other adverse effects, not elsewhere classified }\end{array}$ \\
\hline Complications following infusion, transfusion, and therapeutic injection & T80.5 Anaphylaxis due to serum \\
\hline Other complications of surgical and medical care, not elsewhere classified & $\begin{array}{l}\text { T88.6 Anaphylactic shock due to adverse effect of correctly } \\
\text { administered medication }\end{array}$ \\
\hline Angio-oedema & T78.3 Angio-oedema \\
\hline Urticaria & L50 Urticaria (for all sub-codes) \\
\hline Dermatitis & $\begin{array}{l}\text { L20.8 Other atopic dermatitis } \\
\text { L20.9 Atopic dermatitis, unspecified } \\
\text { L23 Allergic contact dermatitis (for all sub-codes) } \\
\text { L27.2 Dermatitis due to ingested food }\end{array}$ \\
\hline Vasomotor and allergic rhinitis & $\begin{array}{l}\text { J30.0 Vasomotor rhinitis } \\
\text { J30.1 Allergic rhinitis due to pollen } \\
\text { J30.2 Other seasonal allergic rhinitis } \\
\text { J30.3 Other allergic rhinitis }\end{array}$ \\
\hline Asthma & J45.0 Predominantly allergic asthma \\
\hline Toxic effect of contact with venomous animals & $\begin{array}{l}\text { T63.0 Snake venom } \\
\text { T63.1 Venom of other reptiles } \\
\text { T63.2 Venom of scorpion } \\
\text { T63.3 Venom of spider } \\
\text { T63.4 Venom of other arthropods } \\
\text { T63.8 Toxic effect of contact with other venomous animals } \\
\text { T63.9 Toxic effect of contact with unspecified venomous animal }\end{array}$ \\
\hline
\end{tabular}

\section{Results}

Of the 88 patients identified as having anaphylaxis, 45 $(51 \%)$ were male. Patients' ages and possible triggers to anaphylaxis are shown in Table 2. Various systems were involved in these patients as shown in Table 2. In $61(69 \%)$ of them two systems were involved, and in $23(26 \%)$ three systems were involved. Intravenous (IV) antihistamines, IV corticosteroids, IV hydration for hypotension, nebulised bronchodilator, and adrenaline were given to these patients (Table 2). Additional doses of these drugs were given to 25 (28\%) of these patients due to resistance to treatment (non-reversal of clinical abnormalities).
In all, $79(90 \%)$ of the patients were discharged in less than 12 hours, 5 (6\%) between 12 and 24 hours later, and $4(5 \%)$ after 24 hours. Among the patients included in this series, there were no in-hospital deaths, and none of them re-attended for a biphasic reaction associated with anaphylaxis.

\section{Discussion}

Owing to the non-specific nature of anaphylactic symptoms, the diagnosis can easily be overlooked. Physicians with little knowledge of anaphylactic reactions can mistake them for simple allergic reactions. In anaphylaxis, five organ systems are 
TABLE 2. Patient characteristics and presentation

\begin{tabular}{|c|c|}
\hline Characteristic/presentation & $\begin{array}{l}\text { No. }(\%) \text { of } \\
\text { patients }^{\ddagger}\end{array}$ \\
\hline \multicolumn{2}{|l|}{ Sex } \\
\hline Male & $45(51)$ \\
\hline Female & $43(49)$ \\
\hline \multicolumn{2}{|l|}{ Age (years) } \\
\hline $16-24$ & $19(22)$ \\
\hline $25-34$ & $13(15)$ \\
\hline $35-44$ & $19(22)$ \\
\hline $45-54$ & $17(19)$ \\
\hline$\geq 55$ & $20(23)$ \\
\hline \multicolumn{2}{|l|}{ Possible trigger } \\
\hline Drugs & $67(76)$ \\
\hline Food & $12(14)$ \\
\hline Bug bites & $7(8)$ \\
\hline Blood product & $1(1)$ \\
\hline Cleaning material & $1(1)$ \\
\hline \multicolumn{2}{|l|}{ Systems involved* } \\
\hline Cardiovascular & $76(86)$ \\
\hline Skin & $75(85)$ \\
\hline Mucosal & $27(31)$ \\
\hline Gastro-intestinal & $9(10)$ \\
\hline Respiratory & $8(9)$ \\
\hline \multicolumn{2}{|l|}{ Treatment $^{\dagger}$} \\
\hline Intravenous antihistamines & $80(91)$ \\
\hline Intravenous corticosteroids & $37(42)$ \\
\hline Intravenous hydration (for hypotension) & $19(22)$ \\
\hline Nebulised bronchodilator & $4(5)$ \\
\hline Adrenaline & $2(2)$ \\
\hline \multicolumn{2}{|l|}{ Discharged (hours) } \\
\hline$<12$ & $79(90)$ \\
\hline $12-24$ & $5(6)$ \\
\hline$>24$ & $4(5)$ \\
\hline \multicolumn{2}{|c|}{$\begin{array}{l}\text { Two systems were involved in } 61 \text { patients and three s } \\
\text { involved in } 23 \text { patients } \\
\text { Some of the patients received combination therapy } \\
\text { Because of rounding, not all percentages total } 100\end{array}$} \\
\hline
\end{tabular}

primarily involved, namely respiratory, cardiovascular, skin, mucosa, and gastro-intestinal tract. Clinically, symptoms can ensue in one or more system and may entail difficulty in respiration, hypotension, mucosal oedema, itchy skin eruptions, nausea, vomiting, diarrhoea, abdominal cramps, palpitations, and cyanosis. ${ }^{9}$ Patients frequently present to the ED immediately after the onset of such complaints that develop soon after allergen exposure. Therefore, the diagnosis and management of anaphylaxis should also of concern to ED physicians. ${ }^{10}$ Moreover, though anaphylaxis was first described more than 100 years ago, even today its treatment continues to vary and it is commonly misdiagnosed and miscoded..$^{10,11}$

In this series of patients labelled as having allergic reactions, most were monitored by ED physicians only as they were not deemed to have anaphylactic shock and were treated and discharged within 12 hours; basically the symptoms and signs were not considered serious enough to warrant further consultation. According to a study conducted by Campbell et al, ${ }^{10} \mathrm{ED}$ doctors could recognise only $23 \%$ of the patients having anaphylaxis.

Primary care treatment of anaphylaxis includes adrenaline, oxygen, and fluids. ${ }^{7}$ In our study, adrenaline was administered to only $2 \%$ of these patients, despite its proven efficiency. As in our series, the literature also shows that adrenaline has been underused. ${ }^{12}$ The fact that a few of our patients did receive adrenaline shows that for them at least, anaphylaxis was considered a possible diagnosis but was never documented.

Patients diagnosed with anaphylaxis should be provided with self-injectable adrenaline at the time of discharge. However, we established that for these patients vital relevant information pertaining to the appropriate diagnosis and recommendations for future drug treatment were not provided. In our patient series, very few were observed for more than 24 hours, and most were discharged in less than 12 hours. Anaphylaxis can be treated and successfully aborted in the ED and observation units. Subsequently however, such patients should still be referred to a specialist/allergist. ${ }^{7}$ How many of our undiagnosed anaphylaxis patients were referred to a specialist/allergist or reached such a doctor by themselves is not known. Mention of such referrals in ED patient records is extremely variable; 0 to $79 \%$ documentation of referral rates have been described. ${ }^{7}$

A biphasic reaction is defined as recurrence of an allergic reaction developing after 4 and up to 72 hours after the initial reaction..$^{13}$ Such second reactions may be more severe than the first and may entail systems not involved in the first. Biphasic reactions have been observed at rates of 3 to $20 \%$ and may be fatal. ${ }^{14,15}$ Failure of ED doctors to monitor patients for the recommended period, consult appropriate specialist clinics, and arrange follow-up could result in medico-legal liability. It is known that a delay in treatment, especially adrenaline injection, may have negative consequences and could even be fatal. ${ }^{12}$ This study demonstrates the need to provide additional training for ED doctors, who should also be expected to train identified patients about the possibility of future severe reactions during their lifetime. All relevant patients should acquire sufficient awareness and training. To this end, additional regulations should be introduced for the training of ED residents. Our study did not identify 
a reaction that resulted in an anaphylaxis-related death diagnosed in our patient group. However, a retrospective study may not be suitable for exploring such deaths in possibly undiagnosed patients and deaths that might have ensued due to biphasic reactions in patients who were not appropriately followed up.

\section{Conclusion}

Emergency physicians should become more aware of the definition of anaphylaxis. They should also learn to provide appropriate education to such patients and refer them to relevant specialists. Adherence to such recommendations could result in higher quality care and prevent potential medical mistakes.

\section{References}

1. Ben-Shoshan M, Clarke AE. Anaphylaxis: past, present and future. Allergy 2011;66:1-14. cross ref

2. Tupper J, Visser S. Anaphylaxis: a review and update. Can Fam Physician 2010;56:1009-11.

3. Simons FE. Anaphylaxis: recent advances in assessment and treatment. J Allergy Clin Immunol 2009;124:625-36; quiz 637-8. cross ref

4. Bjornsson HM, Graffeo CS. Improving diagnostic accuracy of anaphylaxis in the acute care setting. West J Emerg Med 2010;11:456-61.

5. Sampson HA, Munoz-Furlong A, Campbell RL, et al. Second symposium on the definition and management of anaphylaxis: summary report-Second National Institute of Allergy and Infectious Disease/Food Allergy and Anaphylaxis Network symposium. Ann Emerg Med 2006;47:373-80. cross ref

6. Kay AB. Allergy and allergic diseases. First of two parts. N Engl J Med 2001;344:30-7. cross ref

7. Brown AF, McKinnon D, Chu K. Emergency department anaphylaxis: a review of 142 patients in a single year. J Allergy Clin Immunol 2001;108:861-6. cross ref

8. Neugut Al, Ghatak AT, Miller RL. Anaphylaxis in the United States: an investigation into its epidemiology. Arch Intern Med 2001;161:15-21. cross ref

9. Harduar-Morano L, Simon MR, Watkins S, Blackmore C. Algorithm for the diagnosis of anaphylaxis and its validation using population-based data on emergency department visits for anaphylaxis in Florida. J Allergy Clin Immunol 2010;126:98-104.e4

10. Campbell RL, Hagan JB, Manivannan V, et al. Evaluation of national institute of allergy and infectious diseases/food allergy and anaphylaxis network criteria for the diagnosis of anaphylaxis in emergency department patients. J Allergy Clin Immunol 2012;129:748-52. cross ref

11. Rutkowski K, Dua S, Nasser S. Anaphylaxis: current state of knowledge for the modern physician. Postgrad Med J 2012;88:458-64. cross ref

12. Lieberman P, Decker W, Camargo CA, Jr, Oconnor R, Oppenheimer J, Simons FE. SAFE: a multidisciplinary approach to anaphylaxis education in the emergency department. Ann Allergy Asthma Immunol 2007;98:51923. cross ref

13. Douglas DM, Sukenick E, Andrade WP, Brown JS. Biphasic systemic anaphylaxis: an inpatient and outpatient study. J Allergy Clin Immunol 1994;93:977-85. cross ref

14. Campbell RL, Luke A, Weaver AL, et al. Prescriptions for selfinjectable epinephrine and follow-up referral in emergency department patients presenting with anaphylaxis. Ann Allergy Asthma Immunol 2008;101:631-6. cross ref

15. Smit DV, Cameron PA, Rainer TH. Anaphylaxis presentations to an emergency department in Hong Kong: incidence and predictors of biphasic reactions. J Emerg Med 2005;28:3818. cross ref 